\title{
THYROID AUTOIMMUNITY MAY EFFECT ON MEAN PLATELET VOLUME
}

\section{Dr.Işılay Kalan¹, Dr Şenay Arıkan Durmaz, Dr Şeyma Yavuz², Dr.Ayşe Çarlıoğlu³, Dr.Ramazan Coşar², Dr.Aydın Çifci²}

${ }^{1}$ Kirikkale University Faculty Of Medicine, Department of Endocrinology, Kırıkkale, Turkey ${ }^{2}$ Kirikkale University Faculty Of Medicine, Department of Internal Medicine , Kırıkkale, Turkey. ${ }^{3}$ Kirikkale University Faculty Of Medicine, Department of Dermatology, Kırıkkale, Turkey.

Introduction and Aim: : Mean platelet volume (MPV) is the measure of platelet size. MPV possibly is a simple way to estimate platelet activity.

Mean platelet volume (MPV) is considered a new indicator of atherosclerosis. Activated platelets and subclinical inflammation predispose to create for atherosclerotic heart disease. Larger platelets are metabolically more active than smaller ones and have more protrombotic potential. We have recently demonstrated that MPV levels in Hashimoto's patients tend to be higher than healthy controls even if in euthyroid state. In present study we aimed to investigate a relationship between MPV and autoimmune thyroid disease.

Material and Methods: One-hundred patients with Hashimoto thyroiditis (HASH) [58 euthroid Hashimoto thyroiditis (EHASH) (mean age $43.4 \pm 12.4$ year)] and 42 hypothyroid (HPHASH) (mean age $46.7 \pm 15.5$ year)] and 81 patients with Graves disease (GD) (mean age 38.8 \pm 13.5 year) who referred our endocrinology outpatient clinic due to high thyroid autoantibodies as antithyroid peroksidase(Anti-TPO) and/or antithyroglobuline(Anti-Tg) and/or TSH receptor antibody were included in the study. Fifty-seven (age-matched $46.4 \pm 11.6$ year) euthyroid control subjects were taken into the study. All study population were evaluated by hormonal and platelet parameters.
Results: Serum Anti-TPO levels in all study groups (EHAS $\mathrm{HPHASH}, \mathrm{GD}$ ) were significantly higher than those contr subjects $(p=0,01, p=0,0001, p=0,0001$, respectively). The MPV patients with $\mathrm{EHASH}, \mathrm{HPHASH}, \mathrm{GD}$ were also found significan higher than control group $(p=0,046, p=0,044, p=0,00$ respectively). No statistically significant differences were foul between the other parameters such as the platelet count, plate distribution width and plateletcrit. We found that MPV increas independently of presence of age, sex and TSH in chror autoimmune thyroid diseases $(\beta=0,074, p=0.007)$.There was significant correlation between MPV and anti-TPO leve $(r=0.145, p=0.027)$.

Discussion: Çarlıoğlu et al found that MPV levels are close related with cardiovascular diseases in patients with euthyro Hashimoto's thyroiditis. Euthyroid Hashimoto's thyroiditis patien have greater risk of atherothrombotic complications than healt controls (1). Erikci et al found that patients with subclinic hypothyroidism has been found higher mean platelet volun (MPV) value than control group (2). Our findings also suggest similar interaction between cardiovascular diseases and MF level in all Hashimoto's thyroiditis patients. Our results sugge that patients with euthyroid, hypothyroid, hyperthyro Hashimoto's thyroiditis have higher MPV levels than t healthy controls.

Conclusions: Our findings suggest that change of autoimmun in thyroid gland in patients with chronic autoimmune disease $\mathrm{m}$ be effect on MPV level as well as tend to create cardiovascul risk because of large platelets have more metabolically active.

\section{References:}

1. Carlioglu A, Timur O, Durmaz SA, Ayhan ME. Mean platelet volume in euthyr patients with Hashimoto's thyroiditis.

2. Erikci AA, Karagoz B, Ozturk A, Caglayan S, Ozisik G, Kaygusuz I, Ozata M. Hematology. 2009 Apr;14 